\title{
To Study the Practices and Life Style Skills Management and Its Impact among Diabetic Patients to Prevent Its Complications in the Field Practice Area of Government Medical College, Amritsar
}

\section{Soni $\mathbf{A}^{*}$}

Senior Resident, Dr. B.R Ambedker State Institute of Medical Sciences, Mohali, India

*Corresponding author: Anamika Soni, Senior Resident, Dr. B.R Ambedker State Institute of Medical Sciences, Mohali, India

Received: August 09, 2021; Accepted: September 09, 2021; Published: September 16, 2021

\begin{abstract}
Aims: 1) To assess the regularity to check the RBS and treatment among diabetic patients (>10 years). 2) To assess the life style skills management among Diabetics (>10 years). 3) To study the impact of practices and life style skills management among Diabetics ( $>10$ years).

Settings and Design: A community based cross-sectional study was conducted in rural and urban field practice areas of Government Medical College, Amritsar.

Methods and Materials: A total of 200 diabetic patients who had diabetes equal to or more than 10 years of duration were interviewed using pretested and predesigned questionnaire.

Results: Out of 200 respondents, 50\% (100/200) were from urban area and $50 \%(100 / 200)$ were from the rural area. Out of total, $65(65 \%), 86(86 \%)$ diabetic respondents from rural and urban areas were on regular treatment $(p<0.05)$ and $28(28 \%), 68(68 \%)$ diabetic respondents from rural and urban areas had glucometer, from which 39(39\%), 57(57\%) diabetic respondents from rural and urban areas checked their RBS regularly $(P<0.05)$. Out of total, $2(1 \%)$ respondents were doing physical activity before and $53(26 \%)$ after the disease. $1(1 \%)$ had quit smoking before and $2(1 \%)$ after the disease and $2(1 \%)$ had avoided selected food items before and $134(67 \%)$ after the disease. Out of total 47 diabetic respondents who were without complications -20(95\%), 24(92\%) from rural and urban areas were doing life style modifications, R-19(90\%), $\mathrm{U}-25(96 \%)$ were on regular treatment.R-18(86\%), U-24(92\%) were doing regular check up and R-18(86\%), U-26(100\%) were monitoring blood glucose level on regular basis.
\end{abstract}

Conclusions: The practice to check the RBS on regular basis and regular treatment and life style skill management was poor among diabetic patients which leads to development of complications at early stage among diabetics (>10 years)

Keywords: Diabetes mellitus; Diabetic complications; Regular treatment; Life style skill management, Glucometer

Key messages: Awareness is the Key approach to prevent the early development of complications among diabetics. So, Awareness should be increased on diabetic complications and need for routine evaluation among DM patients.

\section{Introduction}

Diabetes Mellitus (DM) is a fast-growing global problem with huge social, health, and economic consequences because of premature illness and death due to its complications [1]. It accounts to $50-80 \%$ of deaths among people with diabetes [2].

Lack of life style skill management combined with irregularity to check RBS and treatment leads to complications such as blindness, amputation and kidney failure among diabetics at early stage.
If appropriate management of diabetes is achieved then these life-threatening complications can be delayed or prevented. So, aim of the study to assess the practices and life style skills management and its impact among diabetic patients ( $>10$ years) to prevent its complications.

\section{Subjects and Methods}

The cross sectional study was conducted in both rural and urban areas of district, Amritsar. Duration of the study was from $1^{\text {st }}$ January
J Fam Med - Volume 8 Issue 7 - 2021

ISSN : 2380-0658 | www.austinpublishinggroup.com

Soni. (C) All rights are reserved
Citation: Soni A. To Study the Practices and Life Style Skills Management and Its Impact among Diabetic Patients to Prevent Its Complications in the Field Practice Area of Government Medical College, Amritsar. J Fam Med. 2021; 8(7): 1270. 
2017 to $31^{\text {st }}$ December 2017. A list of all the marked houses in village Nagkalan and adjacent villages was obtained. A list of all the wards covered by the UTHC (Urban Training Health Centre) was procured. Out of those, one ward was selected randomly by lottery method and similarly the next to study the diabetic patients. 11000 population was covered i.e. 7500 from rural and 3500 from urban area respectively. In total 200 diabetic patients who had diabetes equal to or more than 10 years of duration was included systematically in the study. Out of which 100 was from the rural and 100 from urban field practice areas. House to house, visit was made by investigator with prior information through field staff. Every house was visited and after explaining, the purpose of study and the informed written consent was taken from the participant who had diabetes equal to or more than 10 years of duration.

\section{Study tool}

A pretested, predesigned, semi-structured questionnaire schedule in local language consisting of items on the demographic profile including age, sex, religion, education, occupation, etc., was used. Questionnaire consisted of items to assess the study the practices and life style skills management and its impact among diabetic patients to prevent its complications. All the questions were asked in vernacular language and pre tested, semi-structured Proformas were filled in.

\section{Inclusion criteria}

The person had diabetes equal to or more than 10 years of duration with or without complications.

Diagnosed diabetic patient for this study was defined as one fulfilling any of the following criteria:

- $\quad$ The patient had a documented evidence of a diagnosis of diabetes (prescription slip/lab reports by qualified Practitioner).

- The patient was taking regular medications for diabetes.

- If the patient was not fulfilling any of the above criteria, then those with random blood sugar more than $200 \mathrm{mg} / \mathrm{dl}$ were included in the study.

\section{Exclusion criteria}

- The person had diabetes less than 10 years of duration with or without complications.

- The patient who were not available after second visit did not included in the study.

- The patient who did not give consent to the study.

\section{Statistical analysis}

The data thus collected was compiled and analyzed statistically using the ratios, proportions and chi square/Yates correction was used as test of significance with $\mathrm{P}<0.05$.

\section{Ethical issues}

All patients were explained the purpose of the study and confidentiality was assured. A written informed consent was taken from each patient before collecting data. The study was approved by the Institutional Ethical Committee of Government Medical College, Amritsar.

\section{Results}

\section{Demographic profile of participants}

Of 200 participants, 50\% (100/200) were each from the urban and rural area. In urban area, there were $60 \%(60 / 100)$ males and $40 \%$ $(40 / 100)$ females while in rural area there were $45 \%$ (45/100) males and $55 \%(55 / 100)$ females who participated in the study. In rural areas, majority were Sikh $(81 \% ; 81 / 100)$ and in urban area, majority were Hindu i.e. (71\% i.e. $71 / 100)$, literate (R-77\%; 77/100 and U-94\%; 94/100) and unemployed (R-55\%; 55/100 and 42\%; 42/100). Mean age of diabetic respondents were 61.08 years in both rural and urban areas as given in Table 1 .

\section{Practices among diabetic respondents (>10 years)}

Out of total $65(65 \%), 86(86 \%)$ diabetic respondents from rural and urban areas were on regular treatment. The association was Table 1: Demographic characteristics of diabetic respondents.

\begin{tabular}{|l|c|c|c|}
\hline Characteristics & Rural (n=100\%) & Urban (n=100\%) & Total (n=200\%) \\
\hline Gender & & & \\
\hline Male & $45(45 \%)$ & $60(60 \%)$ & $105(53 \%)$ \\
\hline Female & $55(55 \%)$ & $40(40 \%)$ & $95(47 \%)$ \\
\hline Religion & & & \\
\hline Hindu & $6(6 \%)$ & $71(71 \%)$ & $77(39 \%)$ \\
\hline Sikh & $81(81 \%)$ & $29(29 \%)$ & $110(55 \%)$ \\
\hline Others & $13(13 \%)$ & $0(0 \%)$ & $13(6 \%)$ \\
\hline Education & & & \\
\hline Illiterate & $33(33 \%)$ & $6(6 \%)$ & $39(20 \%)$ \\
\hline Literate & $67(77 \%)$ & $94(94 \%)$ & $161(80 \%)$ \\
\hline Occupation & & & \\
\hline Unemployed & $55(55 \%)$ & $42(42 \%)$ & $97(48.5 \%)$ \\
\hline Employed & $45(45 \%)$ & $58(58 \%)$ & $103(51.5 \%)$ \\
\hline Age & & & \\
\hline $31-40$ & $5(5 \%)$ & $4(4 \%)$ & $9(4 \%)$ \\
\hline $41-50$ & $20(20 \%)$ & $16(16 \%)$ & $36(18 \%)$ \\
\hline $51-60$ & $39(39 \%)$ & $37(37 \%)$ & $37(37 \%)$ \\
\hline $61-80$ & $36(36 \%)$ & $43(43 \%)$ & $79(40 \%)$ \\
\hline
\end{tabular}

Table 2: Distribution of respondent on the basis of treatment and diabetes $(n=200)$.

\begin{tabular}{|l|c|c|c|}
\hline \multirow{2}{*}{ Treatment } & \multicolumn{2}{|c|}{ Diabetic Respondents } & \multirow{2}{*}{ Total (\%) } \\
\cline { 2 - 3 } & Rural (\%) & Urban (\%) & \\
\hline Regular & $65(65 \%)$ & $86(86 \%)$ & $151(76 \%)$ \\
\hline Irregular & $35(35 \%)$ & $14(14 \%)$ & $49(24 \%)$ \\
\hline Total & $100(100 \%)$ & $100(100 \%)$ & $200(100 \%)$ \\
\hline
\end{tabular}

Table 3: Distribution of respondents on the basis of glucometer and diabetes $(n=200)$.

\begin{tabular}{|l|c|c|c|}
\hline \multirow{2}{*}{ Glucometer } & \multicolumn{2}{|c|}{ Diabetic Respondents } & \multirow{2}{*}{ Total (\%) } \\
\cline { 2 - 3 } & Rural (\%) & Urban (\%) & \\
\hline Yes & $28(28 \%)$ & $68(68 \%)$ & $96(48 \%)$ \\
\hline No & $72(72 \%)$ & $32(32 \%)$ & $104(52 \%)$ \\
\hline Total & $100(100 \%)$ & $100(100 \%)$ & $200(100 \%)$ \\
\hline
\end{tabular}


found significant $(\mathrm{P}<0.05)$ as shown in Table 2 .

Out of total $28(28 \%), 68(68 \%)$ diabetic respondents from rural and urban areas had glucometer as shown in Table 3.

Out of 200,39(39\%), 57(57\%) diabetic respondents from rural and urban areas checked their RBS regularly. The association was found significant $(\mathrm{P}<0.05)$ as shown in Table 4 .

\section{Life skill management among diabetics (>10 years)}

Out of total, 2(1\%) respondents were doing physical activity before and $53(26 \%)$ after the disease. 1(1\%) had quit smoking before and $2(1 \%)$ after the disease and 2(1\%) had avoided selected food items before and 134(67\%) after the disease as shown in Table 5.

Out of total 47 diabetic respondents who were without complications $-20(95 \%), 24(92 \%)$ from rural and urban areas were doing life style modifications. R-19( 90\%), U-25( 96\%) were on regular treatment. R-18(86\%), U-24(92\%) were doing regular check up and R-18(86\%), U-26(100\%) were monitoring blood glucose level on regular basis as shown in Table 6.

\section{Discussion}

The present study was conducted to assess the practices and life style skills management and its impact among diabetic patients to prevent its complications in the field practice area of Government Medical College, Amritsar

A study by Mookambika et al. also stated that $74 \%$ were taking diabetic medication regularly which showed similar result with our Table 4: Distribution of diabetic respondents on the basis of regularity to check $\operatorname{RBS}(n=200)$.

\begin{tabular}{|l|c|c|c|}
\hline \multirow{2}{*}{ Regularity } & \multicolumn{2}{|c|}{ Diabetic Respondents } & \multirow{2}{*}{ Total } \\
\cline { 2 - 3 } & Rural & Urban & \\
\hline Regular & $39(39 \%)$ & $57(57 \%)$ & $96(48 \%)$ \\
\hline Irregular & $61(61 \%)$ & $43(43 \%)$ & $104(52 \%)$ \\
\hline Total & $100(100 \%)$ & $100(100 \%)$ & $200(100 \%)$ \\
\hline
\end{tabular}

$\mathrm{P}<0.05$.

Table 5: Distribution of respondents on the basis of life style modifications $(n=200)$.

\begin{tabular}{|l|c|c|c|}
\hline \multicolumn{1}{|c|}{$\begin{array}{c}\text { Type of life style } \\
\text { modifications }\end{array}$} & $\begin{array}{c}\text { Before Disease } \\
\text { (\%) }\end{array}$ & $\begin{array}{c}\text { After disease } \\
\text { (\%) }\end{array}$ & Total (\%) \\
\hline Physical Activity & $2(1 \%)$ & $53(26 \%)$ & $55(27 \%)$ \\
\hline Reduce body weight & $3(2 \%)$ & $14(7 \%)$ & $17(9 \%)$ \\
\hline Give up alcohol & $5(2 \%)$ & $11(6 \%)$ & $16(8 \%)$ \\
\hline Smoking cessation & $1(1 \%)$ & $2(1 \%)$ & $3(2 \%)$ \\
\hline $\begin{array}{l}\text { Avoidance of selected food } \\
\text { items }\end{array}$ & $2(1 \%)$ & $134(67 \%)$ & $136(68 \%)$ \\
\hline Other pathies & $0(0 \%)$ & $0(0 \%)$ & $0(0 \%)$ \\
\hline
\end{tabular}

Multiple answers permitted.

Table 6: Distribution of diabetic respondents according to reasons for not developing complications $(n=47)$.

\begin{tabular}{|l|c|c|}
\hline \multicolumn{1}{|c|}{ Factors } & Rural (21) & Urban(26) \\
\hline Life style modification & $20(95 \%)$ & $24(92 \%)$ \\
\hline Regular treatment & $19(90 \%)$ & $25(96 \%)$ \\
\hline Regular check up & $18(86 \%)$ & $24(92 \%)$ \\
\hline Glucose monitoring (regularly) & $18(86 \%)$ & $26(100 \%)$ \\
\hline
\end{tabular}

Multiple answers permitted study (Mookambika et al. 2016) [3].

A study by Skelly et al stated that $40 \%$ diabetic respondents had glucometer (Skelly et al., 2005) [4]. Kalayou et al. also stated that $37 \%$ diabetic respondents had glucometer which showed similar results with our study (Kalayou et al., 2012) [5].

A study by Shaji et al. stated that $76.9 \%$ of diabetics monitored their blood glucose levels regularly (Shaji et al., 2013) [6] and Mookambika et al. also stated that $52.5 \%$ diabetic respondents did their blood sugar check up regularly which were observed in our study (Mookambika et al., 2016) [3].

Salvaraj et al. in their study revealed that $45.6 \%$ diabetic respondents were doing physical activity, 58.3\% had avoided the selected food items after being diagnosed with diabetes (Selvaraj, 2018) [7]. A study by Al Bimani et al. stated that $38 \%$ of the diabetic patients were doing regular exercise and $56 \%$ were adhered to the recommended controlled and planned diet and 5.7\% had gave up smoking after being diagnosed with diabetes showed similar results with our study (Al Bimani et al., 2015) [8].

American diabetes association (2018) stated that complications of diabetes can be prevented by life style modifications, regular treatment and periodic check-ups. A study conducted by Padma et al revealed that $71(61.68 \%)$ were aware of importance of exercise for the control of disease while $88(75.21 \%)$ said that modification in diet is essential for the control of the disease and as result of this 75 (64\%) of the respondents had achieved glycemic control (Padma et al., 2012). So it was found that self-care practices, following a controlled diet, regular exercise and compliance with drug were significantly associated with the achieving glycemic control and similar results were observed in our study.

\section{Acknowledgement}

Results revealed poor knowledge and practices towards diabetes. We conclude that there is a need for structured programs to improve attitude and practices of diabetic patients to promote better compliance towards diet, exercise and drug regimen among diabetics. If appropriate management of diabetes is achieved then these lifethreatening complications can be delayed or prevented.

\section{References}

1. WHO. Global report on diabetes. World Health Organization. 2016.

2. Abougalambou SS, Hassali MA, Sulaiman SA, Abougalambou AS. Prevalence of vascular complications among type 2 diabetes mellitus outpatients at teaching hospital in Malaysia. J Diabetes Metab. 2011.

3. Mookambika RV, Nelson SB, Ashok VG. A study on diabetic care among diabetic patients in a tertiary care health centre. Int J Contemporary Med Res. 2016; 3: 3091-3092.

4. Skelly AH, Arcury TA, Snively BM, Bell RA, Smith SL, Wetmore LK, et al. Selfmonitoring of blood glucose in a multiethnic population of rural older adults with diabetes. The Diabetes Educator. 2005; 31: 84-90.

5. Berhe KK, Demissie A, Kahsay AB, Gebru HB. Diabetes self-care practices and associated factors among type 2 diabetic patients in Tikur Anbessa specialized hospital, Addis Ababa, Ethiopia-a cross sectional study. International Journal of Pharmaceutical Sciences and Research. 2012; 3: 4219.

6. Shaji S, Rajendran D, Kumpatla S, Viswanathan V. Evaluation of diabetes self-care with self-monitoring of blood glucose among type 2 diabetic patients and its impact on HbA1c. International Journal of Diabetes in Developing 


\section{Countries. 2013; 33: 181.}

7. Saurabh S, Sarkar S, Selvaraj K, Kar SS, Kumar SG, Roy G. Effectiveness of foot care education among people with type 2 diabetes in rural Puducherry, India. Indian journal of endocrinology and metabolism. 2014; 18: 106.

8. Al Bimani ZS, Khan SA, David P. Evaluation of T2DM related knowledge and practices of Omani patients. Saudi Pharmaceutical Journal. 2015; 23: 22-27.
9. Padma K, Bele SD, Bodhare TN, Valsangkar S. Evaluation of knowledge and self-care practices in diabetic patients and their role in disease management. Natl J Community Med. 2012; 3: 3-6. 